\title{
A milestone for future
}

We are very pleased to publish the following report concerning the "Multiple Birth Roster" established by the New York City Department of Health.

It is our opinion that the use for punched cards for easy reference in twin research will provide the opportunity for much faster, accurate work. The Mendel Institute in Rome is now experimenting in this field and we hope to report in the very near future that the records concerning our several thousands of twin cases are ready in punched-car form.

We advocate an exchange of information among those interested in this work, as standard recording procedures (if allowed by the possibly different equipment) would greatly increase the value of individual projects through possible comparison and combination.

RED.

\section{Multiple Birth Roster}

The New York City Department of Health has established a "Multiple Birth Roster". The Roster is intended to be a scurce of information for research workers in the fields of genetics, child development, etc. The Department will cooperate with researchers to supply them with some data which may be helpful to them to initiate genetic studies.

All multiple births involving at least two live infants are included in the Roster. All the identifying, demographic, and pregnancy information available on the birth certificate of each infant is punched on a tabulating card. A photostatic copy of the complete record of birth is also in the register, so that details not available on the punched card may be conveniently abstracted. The Roster will be kept up-todate in three respects: adoption of a child, deaths during the first year of life, and data fed back to the Roster by the individual researcher. The Roster was initiated as of January I, I $95^{8}$ and will be continued indefinitely. At a later date an evaluation will be made to determine whether its usage by researchers warrants its continuation.

Researchers requesting information from the Roster will be expected to adhere to such requirements as the Department may deem necessary. All requests will be reviewed as to the qualifications of the investigator and the value of the proposed study. Investigators may be asked to allocate clerical staff to assist in selecting the data requested. Facts elicited by home interviews and/or abstract of records are to be made available by the researcher to other researchers to avoid duplications of efforts.

Formal requests should be submitted to Dr. Harold Jacobziner, Assistant Commissioner for Maternal and Child Health Services, New York City Department of Health, I25 Worth Street, New York 13, New York. 